\title{
Teaching Grammar in an Integrated-interactive Framework: Some Pedagogical Applications
}

\author{
Vijay Singh Thakur* \\ English Language and Linguistics in the Department of Languages and Translation, \\ Dhofar University, Sultanate of Oman; vijay_oman@yahoo.co.in
}

\begin{abstract}
Communication always remains one of the central goals in ESL/EFL teaching. If communication is our major objective as language teachers, then interaction, i.e. reception and expression of messages, must be present from the first encounter with the language in the class. In the backdrop of Rivers' [1] premise, that "Communication derives essentially from interaction," this paper argues that grammar needs to be taught in an integrated-interactive framework through what Ellis [2] calls a natural developmental route in the theory of second language acquisition. This involves both instruction and natural exposure to target language and its use in communicative situations. In view of this, an attempt is made to illustrate some functional pedagogical applications of a grammar point of using conditionals in a contextual integrated framework.
\end{abstract}

Keywords: Context-sensitive and Context-effective Language, ESL/EFL Teaching, Exchange, Pre-grammar Stage, Post-grammar Stage

\section{Introduction}

Exchange, to use Well's [3] remark, is the basic unit of discourse, which implies centrality of interaction to become more important in language learning situations. As Rivers [4] argues, "students achieve facility in using a language when their attention is focused on conveying and receiving authentic messages, i.e. messages that contain information of interest to speaker and listener in a situation of importance to both".

From a functional point of view, the information in our head is a living resource that allows us to communicate and be understood. Supposedly, we teach grammar to facilitate communication in the target language. Therefore, the knowledge of grammar should not become merely a dry record of facts and rules. For this reason, Scrivener [5] argues that learning rules from a grammar book by heart is probably not learning grammar and, similarly, reciting grammar rules by heart may not be understanding grammar". Even doing grammar exercises and tests may not necessarily be learning grammar. There is no hard evidence that any of these lead to people being able to use grammar accurately and fluently in speech. In this context, Thornsbury [6] suggests that we could open up our concept of grammar if we start thinking of it as not just a noun (i.e. the information), but as a verb as well (i.e. the active skill of using language).

Before getting down to illustrate as to how grammar could be taught as a verb, it would be in the fitness of our discussion to briefly look at why is it needed to teach grammar in terms of an active skill of using language.

\section{The Need to Teach Grammar as a Dynamic Verb}

A natural language, in the functional paradigm, is seen as an integrated part of Communicative Competence of the natural language user. Incidentally, a natural language, in the first place, is conceptualized as an instrument of establishing communicative relationships. Thus, if learners are to achieve a functional command of language, they will need to be able to understand and produce context-sensitive and context-effective language. Since the introduction

*Author for correspondence 
of Communicative Language Teaching, there has been a lot of progress in the functional teaching of the four primary skills of Listening, Speaking, Reading and Writing (LSRW), but the grammar teaching lagged far behind in this respect. Although some attempts [7-9] have been made to make the grammar teaching contextualized, direct grammar teaching continues to be very common in ESL/EFL classrooms. A lot more still needs to be done to go beyond this movement and bring grammar instruction fully to life and make it purposeful and functional. Grammar Instruction, in most cases, is not integrated into the four skills of LSRW but given in isolation. Mostly it is teachers who formulate the grammar rules on the board. Grammar rules will be clearer and be remembered better when students formulate them themselves than when teachers do them for the students. Furthermore, the rules will be better reinforced if they're put to functional use in language. Grammar should be taught for the language's sake and not merely for grammar's sake. Put another way, grammar teaching should not be restricted to a very narrow, non-communicative range that does not prepare students to use language in everyday life. Thus, a language-based approach needs to be adopted in teaching grammar.

What follows next, after discussing the need for an integrated language-based approach to grammar teaching, is a note on communicative steps of an integrated-interactive lesson, which is followed by a sample grammar lesson. Let us look at communicative steps of the lesson first.

\section{Steps in an Integrated Grammar Lesson}

A communicative grammar lesson, as in teaching LSRW, should involve pre-, while-, and post-stages to provide integrated and interactive learning environments. In the pre-grammar stage, the teacher needs to connect grammar teaching with real life, fuel students' curiosity in the subject, and raise consciousness by discussing the purpose and use of learning. The while-grammar part should help students perceive the new area of thrust in the grammar lesson imparted and make available considerable contribution through subject-specific images, videos, instances, and content. And the post- grammar segment should offer adequate prospect for the pupils to connect the grammar lesson to real life encounters and use it for meaningful application. Put another way, the while-stage elucidates the import of the new construction, whereas the post-stage throws light on the creative and the dynamic facets of the same.
The following is a developmental application of a pre-, while- and post-grammar stage into teaching a sample grammar lesson.

\section{An Integrated Grammar Lesson on Type 1 Condition in English}

Area: Sentence Grammar of Condition

Objective: Teaching First Condition in English through Popular Superstitions

\subsection{Pre-grammar Stage}

This stage offers an opportunity to exploit students' prior knowledge of the subject and set the context and mood for teaching a new grammar point.

- The teacher writes Friday, the 13th on the board and elicits students' knowledge about it and the beliefs associated with it. Gives clues, if necessary, that it is a title; title of an English film; related with superstition(s). Elicits the meaning of 'superstition' through examples, if needed.

- The teacher elicits superstition(s) associated with Friday, the 13th.

- The teacher then shows one of the trailers of the film from you tube, e.g. the trailer entitled, "Friday the 13th part 2 (2013) — official trailer\# 1 [HD]"; 2:38 minutes $<$ from:http://www.youtube.com/watch? $v=N D j U S B W$ $W 1 b I>$. Many video clips are available on you tube about it.

- After showing the trailer of the film, the teacher elicits information using wh-questions such as (a) Is the film scary?; (b) Is the number 13 lucky or unlucky for the people in the film?; (c) What is happening to the people on Friday, the 13th?; etc.

(If showing a video is not possible due to practical constraints then the teacher tells the story of the film in brief or gives students a review of the film to read and elicits and discusses the superstitions that surround the unlucky number 'the 13 ').

- The teacher elicits from students other such beliefs they know.

\subsection{While-grammar Stage}

This stage provides a context for teacher's input and an opportunity for students to notice new grammatical structure.

- The teacher tells the students that they're going to learn a new grammar item, without mentioning the 
name of the grammatical structure for motivational purposes.

- The teacher introduces the structure of type 1 condition specifying that this structure refers to the future, where the condition may or may not be fulfilled, e.g. If it rains, I'll wear a hat or I'll wear a hat if it rains. (Incidentally, it refers to conditions which seem, at least $50 \%$, likely to be fulfilled at the time of speaking [10].

Now the students are ready to be involved in doing the following tasks:

\section{Task 1}

Which of the following in your culture considered lucky/unlucky?

(a) Seeing in a broken mirror

(b) A black cat crossing your way

(c) An urge of scratching your palm

(d) Seeing a crow sitting on your house early in the morning

(e) Someone sneezing at the time you're going out of your house

(f) Getting continuous hiccups

(g) Hearing dogs crying in the midnight

(Answers: Tentative answers could be: (a) unlucky (b) unlucky (c) lucky (d) unlucky (e) unlucky (f) lucky (g) unlucky)

\section{Task 2:}

Write the superstition that the following picture is associated with.

(a)

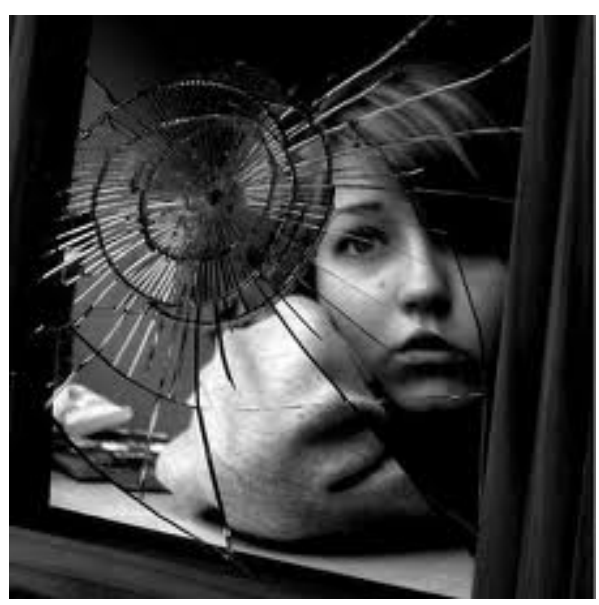

If you

(Answers: (a) If you break/damage a mirror, you will damage your soul and invite bad luck)

\subsection{Post-grammar Stage}

Post-Grammar stage is meant to provide students opportunities to use the learnt item in their speech and writing.

- The teacher asks the students to work in groups and share if they know any superstitions other than the ones introduced and discussed in the lesson. The group leader makes notes of them and finally presents to the rest of the class using the first condition structure.

- Students work in pairs, share, discuss some popular superstitions in their culture and write a paragraph about them.

- Students take up a project, work in groups and explore popular superstitions in the eastern and western countries/cultures on the Internet and write a compare and contrast essay using type 1 conditional structure.

- As an extension activity, students work in groups and make a list of popular moral values such as being honest, helping others, respecting elders, etc and write the advantages/disadvantages of following/flouting them in life using type 1 conditional structure. This activity, and the preceding project work, could be assigned as assessable portfolio tasks for motivational purposes.

\section{Conclusion}

In view of communication being the main goal of language teaching, grammar lessons-like the primary language skills lessons-need to be context-based, integrated and interactive for the purposes of better learner motivation, participation and language development. With this as a backdrop, grammar teachers should provide meaningful instructional input through relevant contexts and sufficient opportunities for students to relate the grammar item(s) to their real-life situations and to put them to authentic use. One of the effective ways in which this could be done is in a smooth and organized transition of pre-, while- and postgrammar stages, as illustrated in this paper.

\section{References}

1. Rivers W.M., "Preface.” ed. Wilga M. Rivers. Interactive Language Teaching. Cambridge: Cambridge University Press, 2000, pp. xi-xvi.

2. Ellis R., Understanding Second Language Acquisition. Oxford: Oxford University Press, 1986, pp. 63.

3. Wells G., Learning through Interaction: The Study of Language Development. Cambridge: Cambridge University Press, 1981, pp. 29. 
4. Rivers W.M., "Interaction as the Key to Teaching Language for Communication.” Interactive LanguageTeaching, Wilga M. Rivers, Ed., Cambridge: Cambridge University Press, 2000, pp. 3-16.

5. Scrivener J., Learning Teaching. Oxford: Macmillan, 2005, pp. 253.

6. Thornsbury S., About Language: Tasks for Teachers of English. Cambridge: Cambridge University Press, 1997.

7. Weaver C., Teaching Grammar in Context. Portsmoutn, N. H.: Boynton/Cook Publishers, Inc., 1996.
8. Mora J.K., "Major Components of the Study of Grammar and Syntax: Teaching Grammar in Context", 2003. Available: http://coe.sdsu.edu/people/jmora/grammar.htm

9. Elbaum S.N., Peman, J.P., Grammar in Context. USA: Heinle \& Heinle Pub, 2006.

10. Aitken R., Teaching Tenses: Ideas for Presenting and Practising Tenses in English. Malaysia: Pearson Education Limited, 2000, pp. 95-105. 